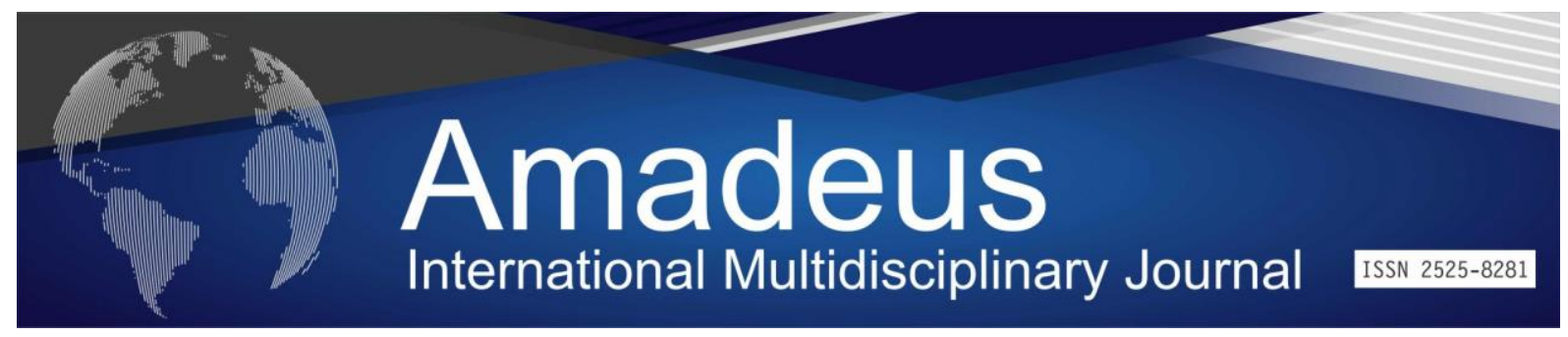

DOI: 10.14295/aimj.v5i9.130

\title{
The Need for Knowledge and use of Vaccines for the Maintenance of Global Health and Development of Countries
}

\section{Maria Natália Alves \\ Ribeiro ${ }^{\text {: }}$; \\ José Leonardo Gomes \\ Coelho ${ }^{2}$; \\ Helenicy Nogueira Holanda \\ Veras $^{3}$; \\ Juliana Ribeiro Francelino \\ Sampaio \\ Emanuela Machado Silva \\ Saraiva \\ Willma José de Santana ${ }^{6}$}

Abstract: Gulobalization promotes changes throughout the world scenario, some not very positive, such as the ease of spreading infectious diseases that threaten global health among different places, which calls for the use of immunization means -see vaccines- so that countries can develop, maintaining health security. The aim of this commentary is to analyze the historical relationship between world well-being and vaccine production. The methodology used was based on studies related to the theme, from 2014-2020, in the languages Portuguese, English and Spanish. The following descriptors were used: vaccines, globalization and health, immunization. This comment is expected to briefly describe the types of vaccines and their importance for maintaining global well-being.

Keywords: vaccines, globalization and health, immunization, global health.

\footnotetext{
${ }^{1}$ Acadêmica de Farmácia do Centro Universitário de Juazeiro do Norte - UNIJUAZEIRO. email: nataliarte14@ gmail.com; ${ }^{2}$ Acadêmico de Farmácia do Centro Universitário de Juazeiro do Norte - UNIJUAZEIRO. ORCID: http://orcid.org/00000001-6028-0807 Email: leonardo-coelho-10@ hotmail.com;

${ }^{3}$ Mestre em Bioprospecção Molecular pela Universidade Regional do Cariri e docente do Centro Universitário Leão Sampaio e do Centro Universitário de Juazeiro do Norte. email: verashelenicy@ gmail.com;

${ }^{4}$ Doutora em Saúde Materno Infantil pelo IMIP-PE Professora do Centro Universitário de Juazeiro do Norte -

UNIJUAZEIRO. email: jrfs22@ hotmail.com ORCID: https://orcid.org/0000-0002-7904-4828;

${ }^{5}$ Mestre em Ciências da Saúde pela Faculdade de Medicina do ABC, Docente da Universidade de Juazeiro do Norte (UNIJUAZEIRO). ORCID: http://orcid.org/0000-0001-8394-5963 email: emanuelams@ @otmail.com;

${ }^{6}$ Pós Doutoranda em Ciências da Saúde - FMABC, Doutora em Ciências Biológicas pela UFPE e Docente do Centro Universitário de Juazeiro do Norte - UNIJUAZEIRO e Faculdade de Tecnologia - FATEC - CARIRI. ORCID http://orcid.org/0000-0003-2733-2892 email: wjsantana@hotmail.com.
} 


\title{
A Necessidade do Conhecimento e do Uso das Vacinas para a Manutenção da Saúde Global e do Desenvolvimento dos Países
}

\begin{abstract}
Resumo: A globalização promove mudanças em todo o cenário mundial, algumas não muito positivas como a facilidade de disseminar doenças infectocontagiosas que ameaçam a saúde global entre diversos lugares, o que urge a necessidade do uso de meios de imunização - vide as vacinaspara que os países possam se desenvolver, mantendo a segurança na saúde. O objetivo deste comentário é analisar a relação histórica entre o bem-estar mundial e a produção de vacinas. A metodologia utilizada foi pautada em estudos relacionados ao tema, dos anos de 2014-2020, nos idiomas Português, Inglês e Espanhol. Foram utilizados os seguintes descritores: vacinas, globalização e saúde, imunização. Espera-se com este comentário descrever de maneira sucinta os tipos de vacinas e a importância dessas para a manutenção do bem-estar global.
\end{abstract}

Palavras-chave: vacinas, globalização e saúde, imunização, saúde global.

\section{Introdução}

Com a globalização e o efeito das tecnologias, o contato entre indivíduos de diversas localidades e culturas diferentes aumentou indubitavelmente. Como consequência dessa aproximação, houve muitas mudanças no cenário mundial, tais como a intensificação das trocas comerciais e também das temidas doenças infecciosas que acabaram se tornando globais, já que a globalização é marcado por uma abertura de inúmeras fronteiras que alcançam pessoas e espaços de maneiras distintas por todo o planeta (Fortes; Ribeiro, 2014).

Entretanto, nem todos os povos possuíam a chamada imunidade contra as doenças que antes lhes eram desconhecidas e sofreram danos imensuráveis. Todavia, o Brasil ao se deparar com a febre por vírus Zika (ZIKV), advindo com indivíduos na Copa do Mundo FIFA de 2014 no Rio de Janeiro, provocando consequências persistentes na sociedade (Oliveira; Vasconcelos, 2016). Momentos semelhantes a esses marcam a necessidade de buscar meios que tornem as populações menos suscetíveis às doenças infectocontagiosas.

Nos primórdios do desenvolvimento das vacinas, as estratégias e os suportes eram muito diferentes, já que a primeira vacina foi produzida no século XVIII por Edward Jenner e Louis Pasteur contra a varíola, na Inglaterra, que conseguiram obter sucesso nas suas 
pesquisas e conquistaram defensores de seu uso, mas também adversários até os dias de hoje (PONTE, 2003). Assim, neste comment, buscar-se-á identificar os tipos de vacinas e sua utilização, bem como a relação histórica destas e da Imunologia em si com a garantia do bemestar mundial.

\section{Método}

Trata-se de um comment (Delmondes; Coelho; Neves; Santana, 2020) que analisou e correlacionou os temas em discussão, através da seleção de onze artigos, publicados em periódicos nacionais e internacionais, entre os anos de 2014 a 2020, também foi utilizado alguns artigos de anos anteriores, porem necessários para elencar alguns aspectos relacionados com o tema. Os dados para esse estudo foram coletados em 2020, nos bancos de dados da SciELO (Scientific Eletronic Library Online) e do LILACS (Literatura LatinoAmericana e do Caribe em Ciências da saúde.

Os critérios de inclusão e exclusão considerados foram: idiomas português, inglês e espanhol, artigos que abrangiam não apenas o Brasil, artigos que tratavam da temática na íntegra, foram desconsiderados os artigos incompletos e aqueles que abordavam a temática de forma surperficial. Os descritores que foram utilizados para identificar os artigos que fundamentaram este estudo foram pesquisados na plataforma DeCs, são eles: "vacinas", "imunização", "globalização" e "globalização and saúde". O cruzamento dos descritores foi feito em combinação única utilizando o operador booleano AND.

\section{Vacinas: do início aos dias de hoje}

As vacinas são aportes importantes para a manutenção da saúde pública pois agem diretamente como profilaxia para diversas doenças provocadas por micro-organismos capazes de desencadear patologias no organismo hospedeiro, assim, são importantes meios de manutenção do estado de saúde individual e global (Viegas et al., 2019).

Tal profilaxia é justificada através do estudo do mecanismo de funcionamento das vacinas, que compreende o uso de componentes dos micro-organismos mortos ou atenuados, partindo do pressuposto de que a existência de um contato anterior com o antígeno ocasiona uma resposta imune eficiente e rápida nos contatos posteriores. As vacinas sofrem constantes 
mudanças provocadas pelo avanço das tecnologias, e hoje são divididas por geração, assim, há vacinas de primeira, segunda e terceira gerações (Braz et al., 2014).

As de primeira geração são aquelas produzidas a partir de micro-organismos vivos amenizados, considerando-se essas como uma das mais eficientes; as de segunda geração são elaboradas por meio de antígenos purificados ou por toxinas inativadas do patógeno e não utilizam a célula; já as de terceira geração são as mais recentes e chamadas de vacinas de DNA, utilizam-se de meios tecnológicos mais avançados como a biotecnologia e valem-se de proteínas dos patógenos ou até mesmo informações genéticas desses (Franco et al., 2019).

Assim, independentemente dos tipos de vacina, todos resultam em uma resposta imune eficaz e são de suma importância para evitar que doenças infectocontagiosas encontrem ambiente favorável para a sua disseminação. Isso é perceptível nos dias de hoje, onde em meio a pandemia do Covid-19 (Novo Coronavírus), o mundo está em pavorosa busca por uma vacina capaz de pôr fim a transmissão desse vírus (Ventura et al., 2020).

A vacinação nos dias de hoje é tão necessária para assegurar o desenvolvimento dos países que foi criada a GAVI (Global Alliance for Vaccine and Immunization) através da junção da OMS, Unicef, Banco Mundial e a Fundação Bill e Melinda Gates e de vários outros países, a fim de que os programas de vacinação dos países sejam fortalecidos e novas tecnologias de imunização sejam introduzidas, voltando seu olhar para os países desenvolvidos e em desenvolvimento (Homma et al., 2011).

\section{A globalização e a necessidade histórica de imunização}

A globalização é um fenômeno que não ocorre apenas em uma esfera social, ela está presente na economia, nas relações sociais, na cultura e na saúde, e busca levar o desenvolvimento. Esse fenômeno ao superar as fronteiras físicas dos países, provoca alterações relevantes capazes de modificarem drasticamente o estado de saúde das pessoas (Fortes; Ribeiro, 2014).

O termo Saúde Global surgiu com o entendimento de que eventos (como doenças infectocontagiosas) que ocorrem em diferentes lugares do mundo não representam apenas ameaças isoladas, ou seja, que tais eventos são ameaças visíveis e potencialmente perigosas para a saúde da população mundial, sendo um termo cunhado com os avanços da Globalização (Ventura, 2016). 
Ademais, ao se falar nesse fenômeno, lembra-se que o ir e vir dos habitantes das inúmeras localidades globais se intensificou nos últimos séculos, e assim, alguns problemas que afetam a saúde global surgiram, principalmente a rápida transmissão de doenças infectocontagiosas, tais como: Ebola, H1N1, Zika vírus, Sarampo, Covid-19, dentre outras, que encontraram uma forma rápida de disseminação entre as pessoas devido ao maior contato que a globalização provoca, causando alarme mundial (Aps et al., 2018).

Assim, a experiência da Globalização, que leva o desenvolvimento para os países, é segura a partir do momento que a garantia da saúde global é mantida. E isso só é possível a partir do conhecimento de métodos de imunização que evitam a repetição de momentos perturbadores nos quais populações foram dizimadas ao terem contato com o que o é propriamente estranho, alguns até mesmo anteriores ao conceito de globalização, como a morte de inúmeros índios ao terem contato com as doenças do homem europeu ainda nos séculos XV-XVIII (Sampaio; Ventura, 2016).

\section{Considerações Finais}

Com este comment, é perceptível ver a histórica relação entre a imunização e a globalização, que nos últimos séculos vêm se fortalecendo, bem como a modificação dos tipos de vacinas que acompanham os avanços da tecnologia de maneira perspicaz. Os métodos da Imunologia garantem a estabilização da Saúde Global diante da constante ameaça de doenças infectocontagiosas serem disseminadas pelo mundo todo por conta da intensa onda de movimentos de pessoas pelo mundo, decorrente da Globalização.

As vacinas criadas ainda no século XVIII por Edward Jenner ainda são de suma relevância para o mundo que vem se transformando, mostrando-se necessárias para a garantia do bem-estar social, como uma ferramenta que não se torna obsoleta, mas que se reinventa e protege de forma eficaz nações inteiras.

Portanto, políticas públicas são necessárias para efetivar tecnologias que possa garantir uma imunização de qualidade para as mais diversas doenças infectocontagiosas, assegurando assim, a manutenção da saúde global e do desenvolvimento dos países 


\section{Referências}

Aps, L. R. D. M. M. et al (2018). Eventos adversos de vacinas e as consequências da não vacinação: uma análise crítica. Revista de Saúde Pública, 52, 40. DOI: https://doi.org/10.11606/S15188787.2018052000384.

Braz, L. C. C. et al (2014). Contribuições da biotecnologia no desenvolvimento e produção de vacinas de primeira, segunda e terceira gerações. Revista Saúde \& Ciência Online, 3(3), 189-206. Disponível em:http://www.ufcg.edu.br/revistasaudeeciencia/index.php/RSC-UFCG/article/view/184

Delmondes, A. P. A., Coelho, J. L. G., Neves, S. A., Santana, W. J. de. (2020). Importância da Contribuição do Profissional Farmacêutico no Controle de Epidemias. Id on Line Rev.Mult.Psic., Julho/2020, vol.14, n.51, p. 408-412. ISSN: 1981-1179.

Fortes, P. A. D. C., \& Ribeiro, H. (2014). Saúde Global em tempos de globalização. Saúde e Sociedade, 23, 366-375. DOI: doi.org/10.1590/S0104-12902014000200002.

Franco, E. O. et al (2019, August). Biotecnologia E Suas Contribuições Para A Evolução Dos Estudos E Da Produção De Vacinas. In Anais Colóquio Estadual de Pesquisa Multidisciplinar (ISSN-25272500) \& Congresso Nacional de Pesquisa Multidisciplinar. Disponível em: http://publicacoes.unifimes.edu.br/index.php/coloquio/article/view/765/671

Homma, A. et al (2011). Atualização em vacinas, imunizações e inovação tecnológica. Ciência \& Saúde Coletiva, 16, 445-458.DOI: doi.org/10.1590/S1413-81232011000200008.

Oliveira, C. S. D., \& Vasconcelos, P. F. D. C. (2016). Microcephaly and Zika virus. Jornal de pediatria, 92(2), 103-105. DOI: 10.1016/j.jped.2016.02.003.

Ponte, C. F. (2003). Vacinação, controle de qualidade e produção de vacinas no Brasil a partir de 1960. História, Ciências, Saúde-Manguinhos, 10, 619-653. DOI: 10.1590/S0104-59702003000500009

Sampaio, J. R. C., \& Ventura, M. (2016). A emergência do conceito saúde global: perspectivas para o campo da saúde coletiva. Cadernos Ibero-Americanos de Direito Sanitário, 5(4), 145-155. DOI: http://dx.doi.org/10.17566/ciads.v5i4.319.

Ventura, D. D. F. L. (2016). Do Ebola ao Zika: as emergências internacionais e a securitização da saúde global. Cadernos de Saúde Pública, 32, e00033316. DOI: 10.1590/0102-311X00033316.

Ventura, D. D. F. L. et al (2020). Desafios da pandemia de COVID-19: por uma agenda brasileira de pesquisa em saúde global e sustentabilidade. Cadernos de Saúde Pública, 36, e00040620. DOI: 10.1590/0102-311X00040620.

Viegas, S. M. F. et al (2019). Preciso mesmo tomar vacina? Informação e conhecimento de adolescentes sobre as vacinas. Avances en Enfermería,37(2), 217-226. DOI: 10.15446/av.eferm.v37n2.76713.

\section{How to cite this article (APA format):}

Ribeiro, Maria Natália Alves; Coelho, José Leonardo Gomes; Veras, Helenicy Nogueira Holanda; Sampaio, Juliana Ribeiro Francelino; Saraiva, Emanuela Machado Silva; Santana, Willma José de. (2020). The Need for Knowledge and use of Vaccines for the Maintenance of Global Health and Development of Countries. Am. In. Mult. J., Jul to Out. (9) 5, 84-89.

Received: 08/05/2020; Accepted: 08/11/2020. 